\title{
Replicative Activity of Hepatitis B Virus Is Negatively Associated with Methylation of Covalently Closed Circular DNA in Advanced Hepatitis B Virus Infection
}

\author{
Jin-Wook Kim ${ }^{a, b}$ Sang Hyub Lee ${ }^{a, b}$ Young Soo Park ${ }^{a, b}$ Jin-Hyeok Hwang ${ }^{a, b}$ \\ Sook-Hyang Jeong ${ }^{a, b}$ Nayoung Kim ${ }^{a, b}$ Dong Ho Lee ${ }^{a, b}$ \\ a Department of Medicine, Seoul National University Bundang Hospital, Seongnam, and \\ ${ }^{b}$ Department of Internal Medicine, Seoul National University College of Medicine, Seoul, South Korea
}

\author{
Key Words \\ Covalently closed circular DNA - Hepatitis B virus • \\ Liver cirrhosis $\cdot$ Methylation $\cdot$ Transcription
}

\begin{abstract}
Objectives: The aim of this study was to examine the methylation status of intrahepatic hepatitis B virus (HBV) covalently closed circular DNA (cccDNA) and to elucidate the possible relationship between the cccDNA methylation and viral replicative activity in patients with HBV-related liver cirrhosis (HBV-LC). Methods: The methylation status of HBV cccDNA was investigated by bisulfite sequencing in nonneoplastic tissues from 12 patients with HBV-LC who underwent surgical resection for combined hepatocellular carcinoma. Clini$\mathrm{cal}$, biochemical and virologic factors were evaluated with respect to the degrees of cccDNA methylation. We also examined the effect of methylation of cccDNA on viral transcription by an in vitro transcription assay. Results: Variable degrees of $\mathrm{CpG}$ methylation were present in the HBV cccDNA from patients with HBV-LC. Old age, low serum HBV DNA levels and low virion productivity were significantly associated with elevated cccDNA methylation. Virion productivity of cccDNA was also lower in HepAD38 cells with a higher degree of cccDNA methylation. In vitro transcription assays showed that the transcriptional activity of HBV ccCDNA was
\end{abstract}

suppressed by increased methylation of cccDNA. Conclusions: Increased CpG methylation of cccDNA is associated with old age, low serum HBV DNA levels and suppressed replicative activity in HBV-LC.

Copyright $\odot 2011$ S. Karger AG, Basel

\section{Introduction}

The hepatitis B virus (HBV) has a 3.2-kb partially double-stranded relaxed circular DNA (rcDNA) genome that is converted into a covalently closed circular DNA (cccDNA) in the nuclei of infected hepatocytes. HBV cccDNA is clinically important because (1) it serves as a template for viral transcription [1] and (2) it is responsible for failure of viral clearance after antiviral therapy [2]. Recent reports have shown that the replicative activity of intrahepatic HBV cccDNA varies widely in chronic hepatitis $\mathrm{B}(\mathrm{CHB})[3,4]$. The host immune response and viral mutations have been proposed as the factors regulating the transcriptional activity of the cccDNA, but the exact mechanisms of transcriptional control of cccDNA are poorly understood [5].

The HBV genome that is integrated into the host DNA can be methylated [6], and previous studies demonstrated regulation of gene expression by methylation of integrat- 
Table 1. Characteristics of the patients and status of HBV cccDNA methylation

\begin{tabular}{lllllll}
\hline $\begin{array}{l}\text { Pa- } \\
\text { tient }\end{array}$ & $\begin{array}{l}\text { Age } \\
\text { years }\end{array}$ & Sex & HBeAg & HBeAb & $\begin{array}{l}\text { Serum HBV DNA } \\
\log _{10} \text { copies/ml }\end{array}$ & $\begin{array}{l}\text { HBV cccDNA } \\
\text { methylation, \% }\end{array}$ \\
\hline P1 & 65 & M & + & - & 6.12 & 44.4 \\
P2 & 47 & M & + & - & 6.74 & 20.0 \\
P3 & 59 & M & + & - & 7.43 & 50.0 \\
P4 & 40 & M & + & - & 7.47 & 15.4 \\
P5 & 39 & M & + & - & 7.77 & 13.3 \\
P6 & 55 & M & - & + & ND & 38.5 \\
P7 & 59 & M & - & + & ND & 50.0 \\
P8 & 64 & M & - & - & ND & 55.6 \\
P9 & 48 & M & - & + & 4.56 & 0 \\
P10 & 48 & F & - & + & 5.63 & 26.7 \\
P11 & 42 & M & - & + & 7.09 & 0 \\
P12 & 34 & M & - & + & 7.99 & 0 \\
\hline
\end{tabular}

$\mathrm{ND}=$ Not detectable

ed HBV DNA [7-10]. In contrast, the methylation status of episomal HBV cccDNA was not known until recently, when two independent groups reported the presence of methylation in the HBV cccDNA [11, 12]. These reports also showed an association between methylation and suppressed HBV replication in CHB. However, the impact of cccDNA methylation on the regulation of $\mathrm{HBV}$ gene expression has not yet been established.

Patients with HBV-related liver cirrhosis (HBV-LC), an end result of long-standing $\mathrm{CHB}$, show wide variability of HBV levels in serum and liver [13]. However, it is not known whether the replicative activity of cccDNA is also variable in HBV-LC. Nor has the methylation of cccDNA been reported in HBV-LC. In this study, we studied the methylation status of intrahepatic HBV cccDNA in patients with HBV-LC by bisulfite sequencing, and assessed the association between cccDNA methylation and the replicative activity of HBV in these patients. We also tried to elucidate the effect of methylation on the transcriptional activity of HBV cccDNA molecules by in vitro transcription assay.

\section{Patients and Methods}

\section{Subjects}

The protocol of this study was approved by our hospital's institutional review board, and written informed consent was obtained from all patients. Twelve consecutive HBsAg-positive patients with well-compensated (Child-Pugh class A) liver cirrhosis who underwent surgical resection of combined hepatocellular carcinoma were enrolled in this study. The characteristics of the patients are summarized in table 1 . No patient had a prior history of antiviral therapy for HBV or chemotherapy for hepatocellular carcinoma. Fresh nonneoplastic liver tissue was obtained from the hepatectomy specimens in the operating room and was immediately processed as described below for the study of $\mathrm{HBV}$ cccDNA.

\section{Cell Lines and Culture Conditions}

The HepAD38 cell line, which produces HBV pregenomic RNA under the control of the tetracycline-responsive CMV-IE promoter (a generous gift from professor C. Seeger, Fox Chase Cancer Center, Philadelphia, Pa., USA), was maintained as described elsewhere [14]. To explore the effect of inhibition of de novo methylation, 5-aza-2'-deoxycytidine (5-aza; Sigma A3656) was replenished daily in the culture medium (final concentration of $2 \mu \mathrm{M})$.

\section{Isolation of $H B V \operatorname{cccDNA}$ and $r c D N A$}

HBV cccDNA was extracted by using a modified Hirt extraction procedure $[15,16]$. Briefly, approximately $50 \mathrm{mg}$ of each fresh nonneoplastic hepatectomy specimen was homogenized in a Potter-Elvehjem tissue grinder with $2 \mathrm{ml}$ of cell lysis buffer [50 $\mathrm{mM}$ Tris-HCl (pH 8.0), $1 \mathrm{~mm} \mathrm{EDTA,} 0.2 \% \mathrm{NP}-40,150 \mathrm{mM} \mathrm{NaCl}]$ at $4^{\circ}$. The homogenate was centrifuged at $16,000 \mathrm{~g}$ at $4^{\circ}$ for $10 \mathrm{~min}$ to isolate the nuclei, and the supernatant was saved for extraction of cytoplasmic HBV rcDNA and HBV RNA. The nuclear pellet was then treated with the same volume of nuclear lysis buffer (6\% SDS, $0.1 \mathrm{~N} \mathrm{NaOH}$ ), neutralized by the addition of $1 / 4$ volume of $3 \mathrm{M}$ potassium acetate $(\mathrm{pH} 5)$ and centrifuged. The supernatant was extracted twice with phenol, and the cccDNA fraction was recovered by ethanol precipitation. Potential contaminating genomic DNA was further removed by treatment with Plasmid-Safe DNase (Epicentre Biotechnologies, Madison, Wisc., USA), and the absence of contaminating genomic DNA was confirmed by the negative PCR results obtained with a primer pair for $\beta$-globin [17]. For isolation of HBV cccDNA from the HepAD38 cell line, cells that were grown in a $60-\mathrm{mm}$ tissue culture dish were lysed by the addition of $0.4 \mathrm{ml}$ of cell lysis buffer and incubated for 5-10 min on ice, and the lysate was centrifuged as described above.

Detection of HBV cccDNA was performed by selective PCR amplification with HBV cccDNA-specific primers as described elsewhere $[18,19]$. The cytoplasmic HBV rcDNA fraction was treated with proteinase $\mathrm{K}$, phenol extracted and ethanol precipitated. Quantification of HBV rcDNA and cccDNA was conducted using the Applied Biosystems 7500 Real-Time PCR System (Applied Biosystems, Foster City, Calif., USA) as described elsewhere $[20,21]$. To confirm the absence of contaminating rcDNA in the cccDNA fraction, Southern blot was performed as reported elsewhere, with minor modifications [22]. Briefly, HBV DNA from HepAD38 cells was subjected to electrophoresis in a $1.5 \%$ agarose gel and transferred onto Nylon membrane (Roche Applied Science). The 462-bp HBV DNA was amplified by using the sense primer HB7F and antisense primer HB7R as reported elsewhere [23]. The PCR product was amplified again by using the single sense primer to generate single-stranded digoxigenin-labeled probes for hybridization [24]. Hybridization and detection were performed by using the DIG high prime DNA labeling and detection starter kit II (Roche Applied Science) according to the manufacturer's instructions. 


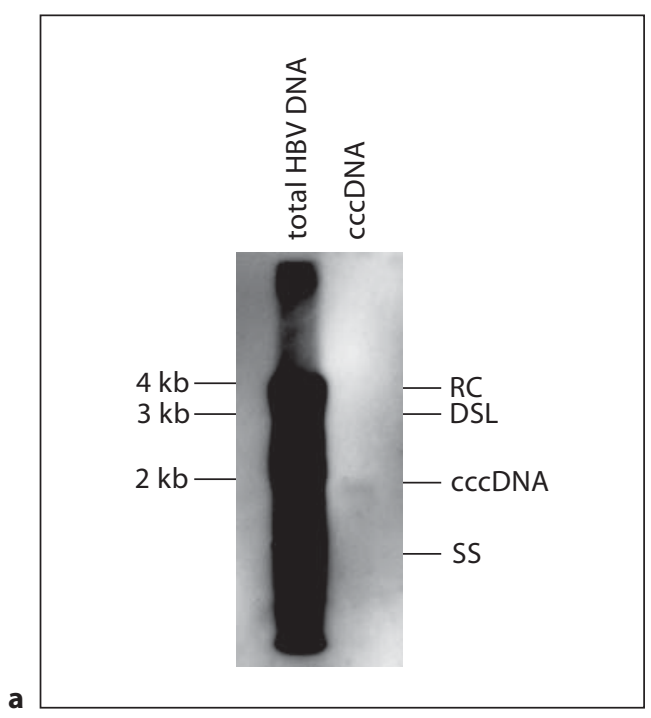

Fig. 1. Bisulfite sequencing of HBV cccDNA from patients with HBV-LC. a Southern blotting confirmed the absence of rcDNA (RC), double-stranded linear DNA (DSL) and single-stranded DNA (SS) in the Plasmid-Safe DNase-treated cccDNA fraction that was used for bisulfite sequencing. $\mathbf{b}$ CpG dinucleotides on the $H B X$ region (13191670) are marked in bold. Fig. 1. c-e Alignment of the $H B X$ sequences from $\mathrm{HBeAg-}$ positive patients (c), HBeAg-negative patients (d) and a negative control (e). Filled and open circles correspond to methylated and unmethylated CpG dinucleotides, respectively.

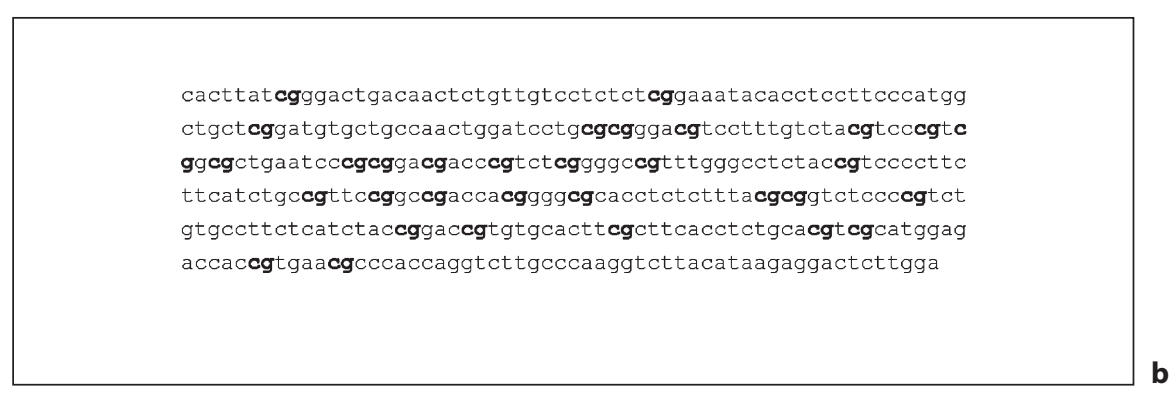

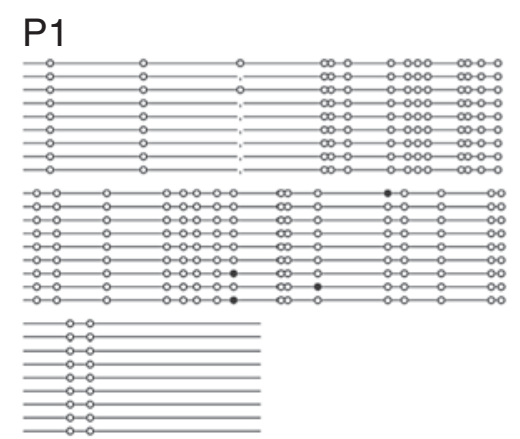

P2

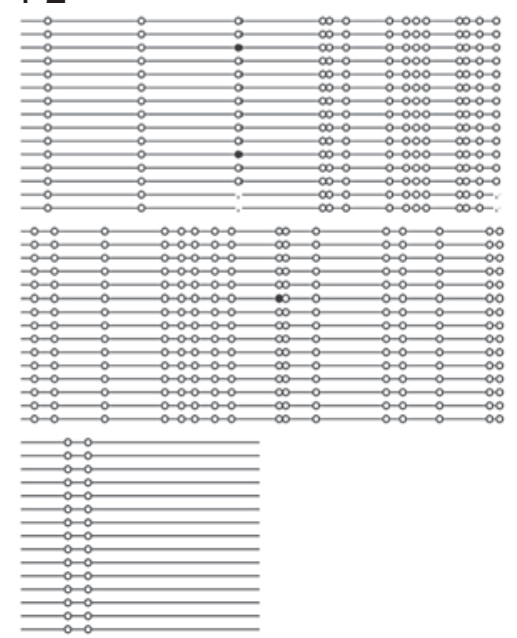

P4

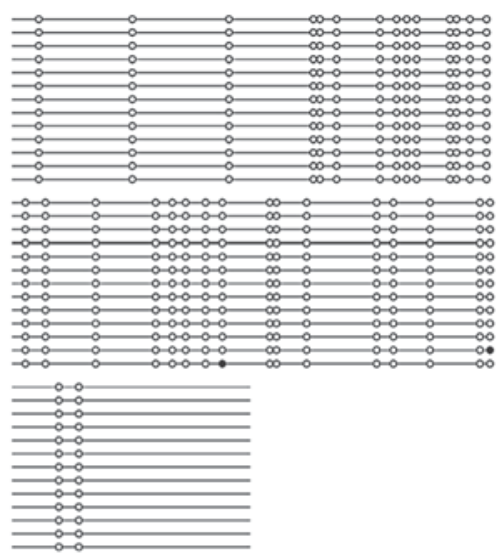

P5

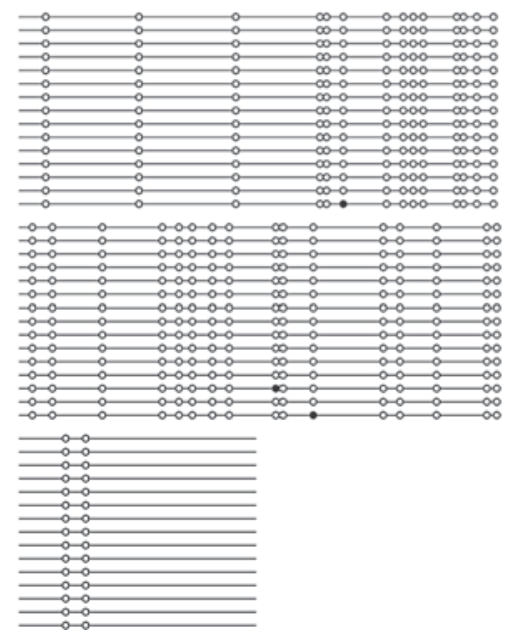

P3

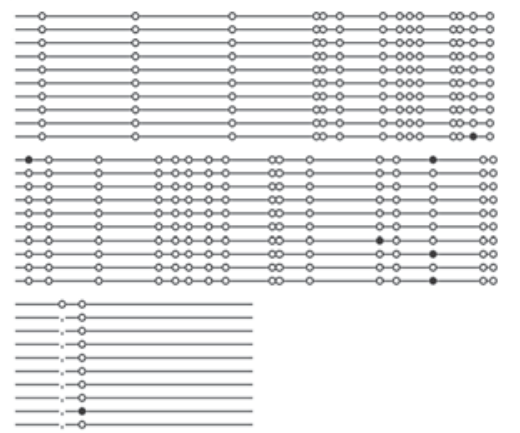

c 


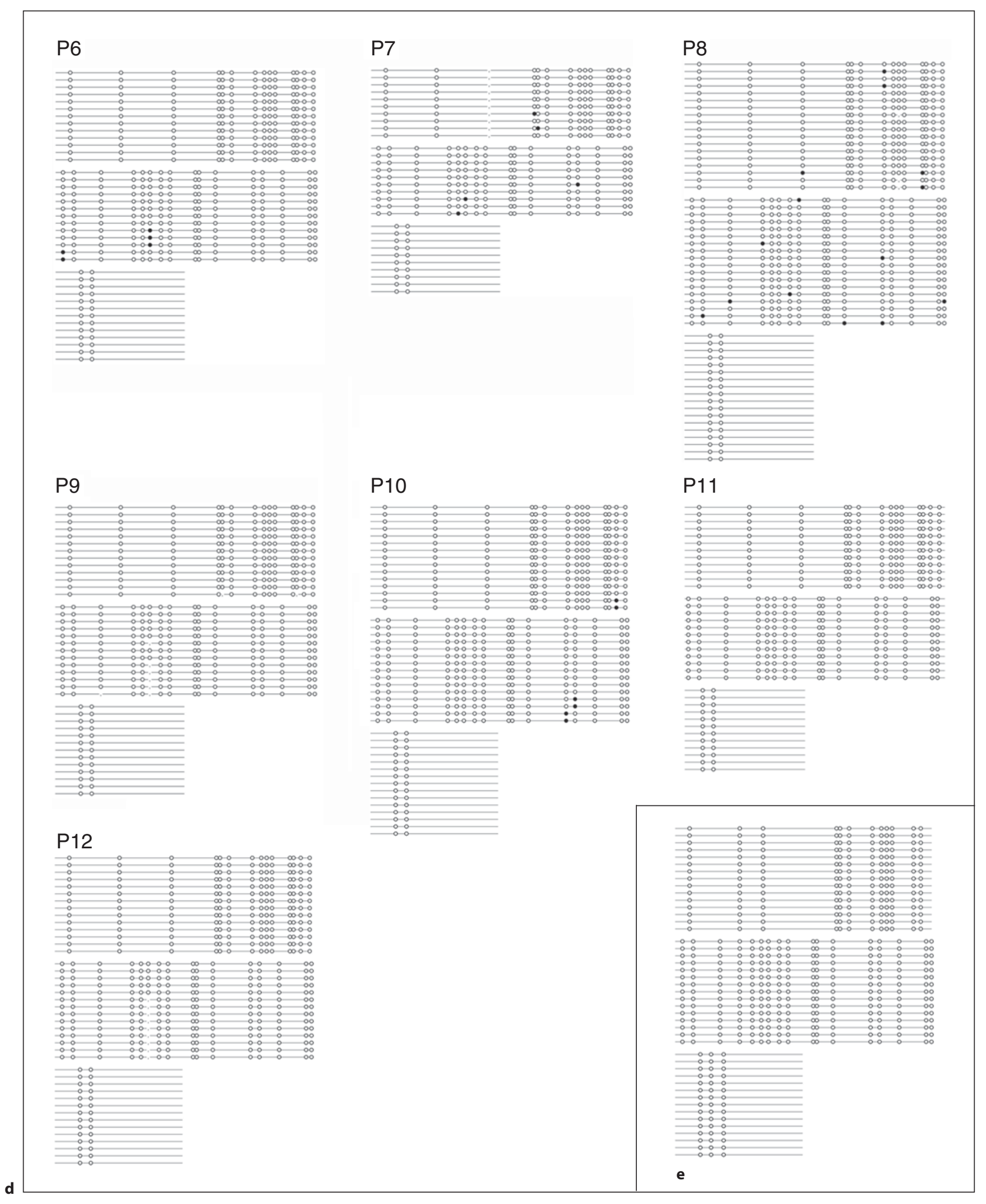


Quantitation of Hepatic HBV RNA

Total RNA was extracted from the cytoplasmic fraction of liver tissues using Trizol (Invitrogen). Transcript-specific quantitative RT-PCR was performed using the PGP (5'-CACCTCTGCCTAATCATC-3') and BC1 (5'-GGAAAGAAGTCAGAAGGCAA- $3^{\prime}$ ) primer pair to measure the HBV RNA [3]. The RNA levels were compared by the relative comparative threshold method with glyceraldehyde-3-phosphate dehydrogenase as an internal loading control. The transcriptional activity of cccDNA was estimated by the relative amount of HBV RNA synthesized per HBV cccDNA molecule $[3,4]$.

\section{Bisulfite Sequencing}

Cytosine methylation of HBV cccDNA was assessed by bisulfite modification of HBV cccDNA as described elsewhere [25, 26], followed by bisulfite sequencing PCR analysis [27]. The PCR primers were designed using MethPrimers [27] [forward (13271352), 5'-GGGATTGATAATTTTGTTGTTTTTTT-3'; reverse (1642-1670), 5'-TCCAAAAATCCTCTTATATAAAACCTTAA$\left.3^{\prime}\right]$ to amplify the bisulfite-modified $H B X$ gene region (nucleotide position 1327-1670), which corresponds to CpG island 2 of Vivekanandan et al. [28] and shows the highest CpG density in the $\mathrm{HBV}$ genome. For a negative control, the same $H B X$ region before bisulfite modification was amplified by PCR from HepAD38 cells (forward primer, 5'-GCAGCAGGTCTGGAGCAAACA-3'; reverse primer, 5'-CATTGCAGAGAGTCCAAGAGTCCTC-3') and cloned into pDrive TA cloning vector (Qiagen). The cloned plasmid (pDrive-HBX) was propagated in $\mathrm{dam}^{-} / \mathrm{dcm}^{-}$Escherichia coli (New England Biolabs, Ipswich, Mass., USA), bisulfite modified and sequenced as described above.

\section{In vitro Transcription Assay}

Nuclear extracts were prepared from Huh7 cells exactly as described previously [29]. The run-off transcription assay was set up as reported previously $[29,30]$. Final concentrations for the reaction included $7 \mathrm{mg} / \mathrm{ml} \mathrm{Huh} 7$ nuclear extract and $5 \times 10^{5}$ copies/ $\mathrm{ml}$ HBV cccDNA. The transcription reaction was performed for $45 \mathrm{~min}$ at $30^{\circ}$ and was treated with DNase I for $30 \mathrm{~min}$ at $37^{\circ}$ to remove template cccDNAs. The RNA was reverse transcribed using random hexamers and amplified by $\mathrm{HBV}$ cccDNA-specific primers as described above.

\section{Chromatin Immunoprecipitation}

The presence of methyl-CpG-binding proteins (MBPs) on HBV cccDNA was studied by chromatin immunoprecipitation as described elsewhere [31-33]. Anti-methyl-CpG-binding domain protein 1 (MBD1; sc-9395) and anti-DNA methyltransferase 3a (DNMT3a; sc-10232) antibodies were purchased from Santa Cruz Biotechnology (Santa Cruz, Calif., USA). Anti-MeCP2 (ab2828) antibodies were purchased from Abcam (Cambridge, UK).

\section{Statistical Analysis}

Continuous variables were compared between different subgroups by Student's t test. Fisher's exact test was used for the analysis of categorical variables. Statistical calculations were performed with SPSS software package version 15 (SPSS Inc., Chicago, Ill., USA).

\section{Results}

Variable Degrees of Methylation Were Present in $\mathrm{HBV}$ cccDNA from $H B V-L C$

The results of bisulfite sequencing are summarized in figure 1. Among the 12 studied patients with HBV-LC, 9 patients showed methylation in HBV cccDNA isolated from liver cirrhosis tissues; methylated $\mathrm{CpG}$ dinucleotides were identified in all $5 \mathrm{HBeAg}$-positive patients (fig. 1c) and 4 of $7 \mathrm{HBeAg-negative} \mathrm{patients} \mathrm{(fig.} \mathrm{1d)}$ by bisulfite sequencing. The possibility of false-positive results due to incomplete bisulfite conversion of $\mathrm{HBV}$ cccDNA was excluded by showing that methylation was absent in the pDrive-HBX plasmid that was propagated in $\mathrm{dam}^{-} / \mathrm{dcm}^{-}$E. coli (fig. 1e). The HBV cccDNA methylation ratio (the percentage of methyl CpG-positive cccDNA clones) varied widely among the patients, ranging from 0 to $55.6 \%$ (table 1). The average HBV cccDNA methylation ratios were not different between $\mathrm{HBeAg}$ positive and HBeAg-negative patients ( 28.6 vs. $24.4 \%$, respectively; $\mathrm{p}=0.747)$. The sites of methylation were also variable, even in cccDNA molecules from the same patient. The methyl-CpGs were dispersed over the sequenced $H B X$ area without a favored CpG site. These findings indicate that $\mathrm{HBV}$ cccDNA molecules are heterogeneous in terms of methylation in patients with HBV-LC.

\section{Factors Associated with Methylation of $\mathrm{HBV}$ cccDNA}

Next, we sought to identify clinical, biochemical and virologic factors which may be associated with methylation of HBV cccDNA. Older age and lower serum HBV DNA titers were significantly associated with increased HBV cccDNA methylation, whereas biochemical parameters were not different between the high- and low-methylation groups (table 2).

\section{Replicative Activity of HBV Is Negatively Associated} with CpG Methylation of HBV cccDNA in HBV-LC

Since methylation of HBV cccDNA was associated with low serum HBV DNA titers, we wanted to know whether the methylation is associated with the amount or activity of intrahepatic HBV cccDNA. There was no correlation between HBV cccDNA methylation and the amount of intrahepatic cccDNA (fig. 2a), and the cccDNA levels were not different between the groups with low $(\leq 0.2)$ and high $(>0.2)$ methylation ratios $(4.7$ \pm 0.9 and $5.2 \pm 1.8 \log _{10}$ copies/mg tissue, respectively; $\mathrm{p}=0.628)$. In contrast, the virion productivity, an indicator of HBV replicative activity [4], was negatively cor- 

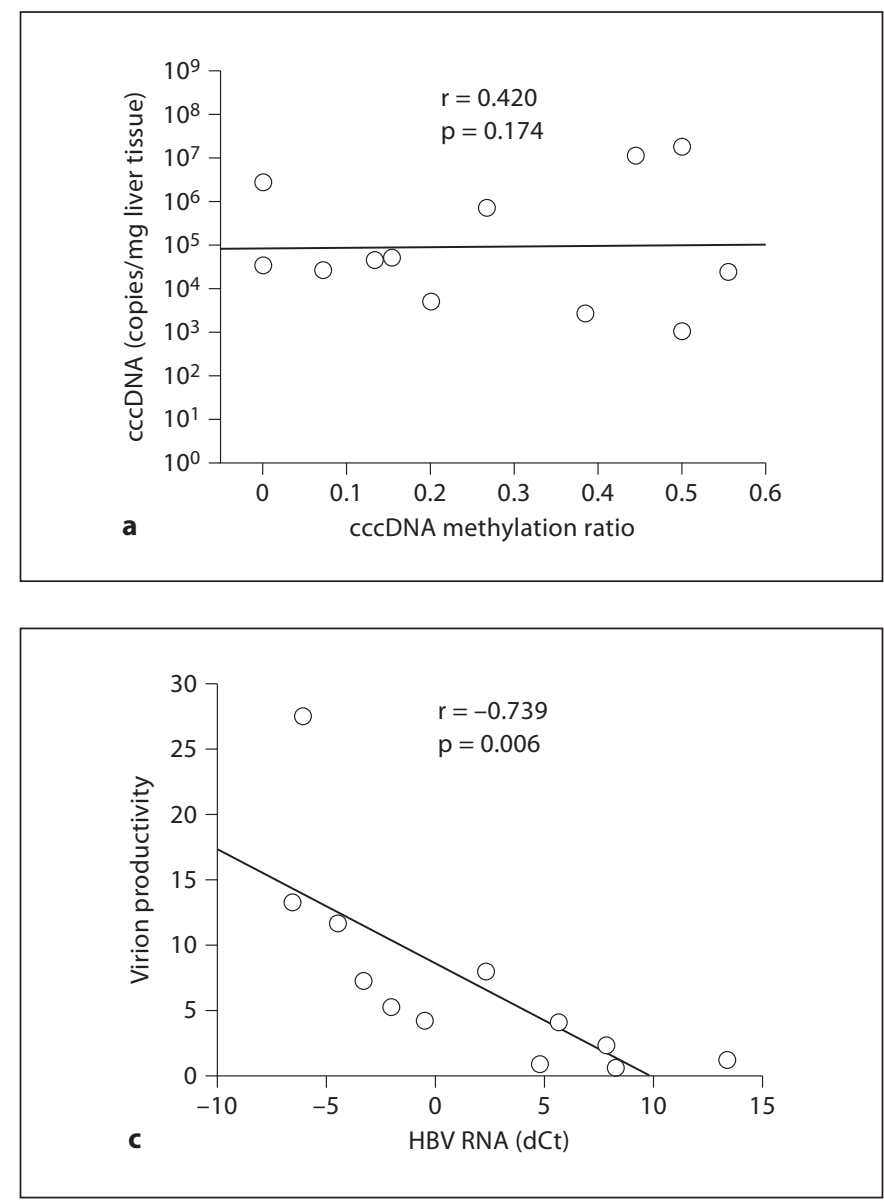

Fig. 2. Correlation between intrahepatic HBV replicative activity and cccDNA methylation in patients with HBV-LC. a There was no significant correlation between the HBV cccDNA methylation ratio and the amount of cccDNA. b In contrast, the virion productivity (defined as the ratio of cytoplasmic rcDNA to intranuclear cccDNA [4]) and the methylation ratio were negatively cor-
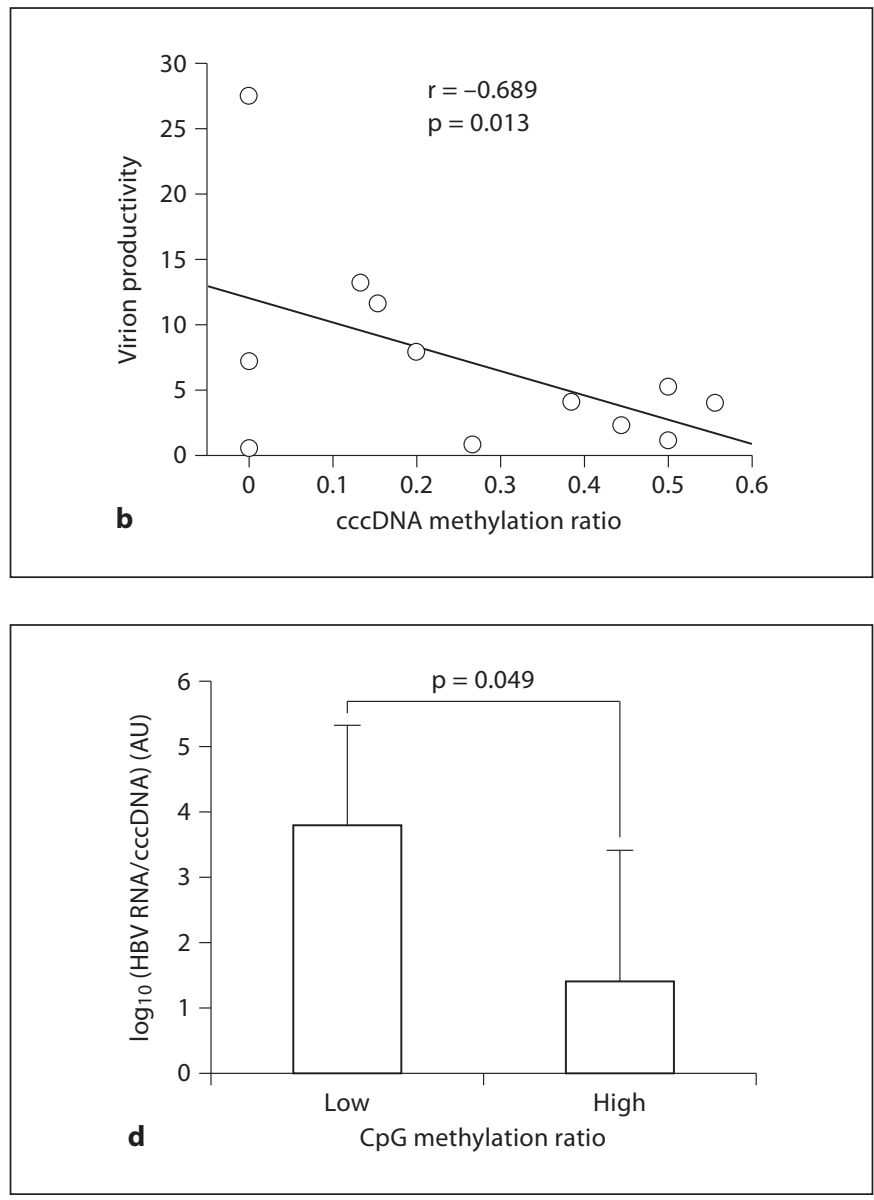

related. c The HBV RNA levels correlated with virion productivity $\left(\mathrm{dCt}=\mathrm{Ct}_{\mathrm{HBV}}-\mathrm{Ct}_{\mathrm{GAPDH}}\right.$, where $\mathrm{Ct}$ is the comparative threshold). d The relative HBV RNA copy numbers produced per cccDNA molecule were significantly higher in patients with a low cccDNA methylation ratio $(\leq 0.2)$ compared to those with a high methylation ratio $(>0.2)$. AU $=$ Arbitrary unit.

Table 2. Variables associated with the degree of HBV cccDNA methylation

\begin{tabular}{lccc}
\hline Variable & $\begin{array}{l}\text { Low HBV cccDNA } \\
\text { methylation ratio } \\
(\leq 0.2 ; \mathrm{n}=6)\end{array}$ & $\begin{array}{l}\text { High HBV cccDNA } \\
\text { methylation ratio } \\
(>0.2 ; \mathrm{n}=6)\end{array}$ & $\begin{array}{l}\mathrm{p} \\
\text { value }\end{array}$ \\
\hline Age, years & $41.7 \pm 5.2$ & $58.3 \pm 6.3$ & 0.001 \\
AST, IU/l & $71 \pm 53$ & $40 \pm 23$ & 0.230 \\
ALT, IU/l & $72 \pm 66$ & $38 \pm 29$ & 0.278 \\
Bilirubin, mg/dl & $0.8 \pm 0.1$ & $0.8 \pm 0.4$ & 0.928 \\
Albumin, g/dl & $4.2 \pm 0.5$ & $4.2 \pm 0.2$ & 0.694 \\
Prothrombin time, INR & $1.09 \pm 0.07$ & $1.10 \pm 0.11$ & 0.905 \\
HBeAg, positive/negative & $3 / 3$ & $4 / 2$ & 0.558 \\
Serum HBV DNA, $\log _{10}$ copies/ml & $6.93 \pm 1.25$ & $4.84 \pm 1.79$ & 0.041 \\
\hline
\end{tabular}

Quantitative variables are expressed as means \pm SD. AST $=$ Aspartate aminotransferase; ALT = alanine aminotransferase; INR = international normalized ratio. 

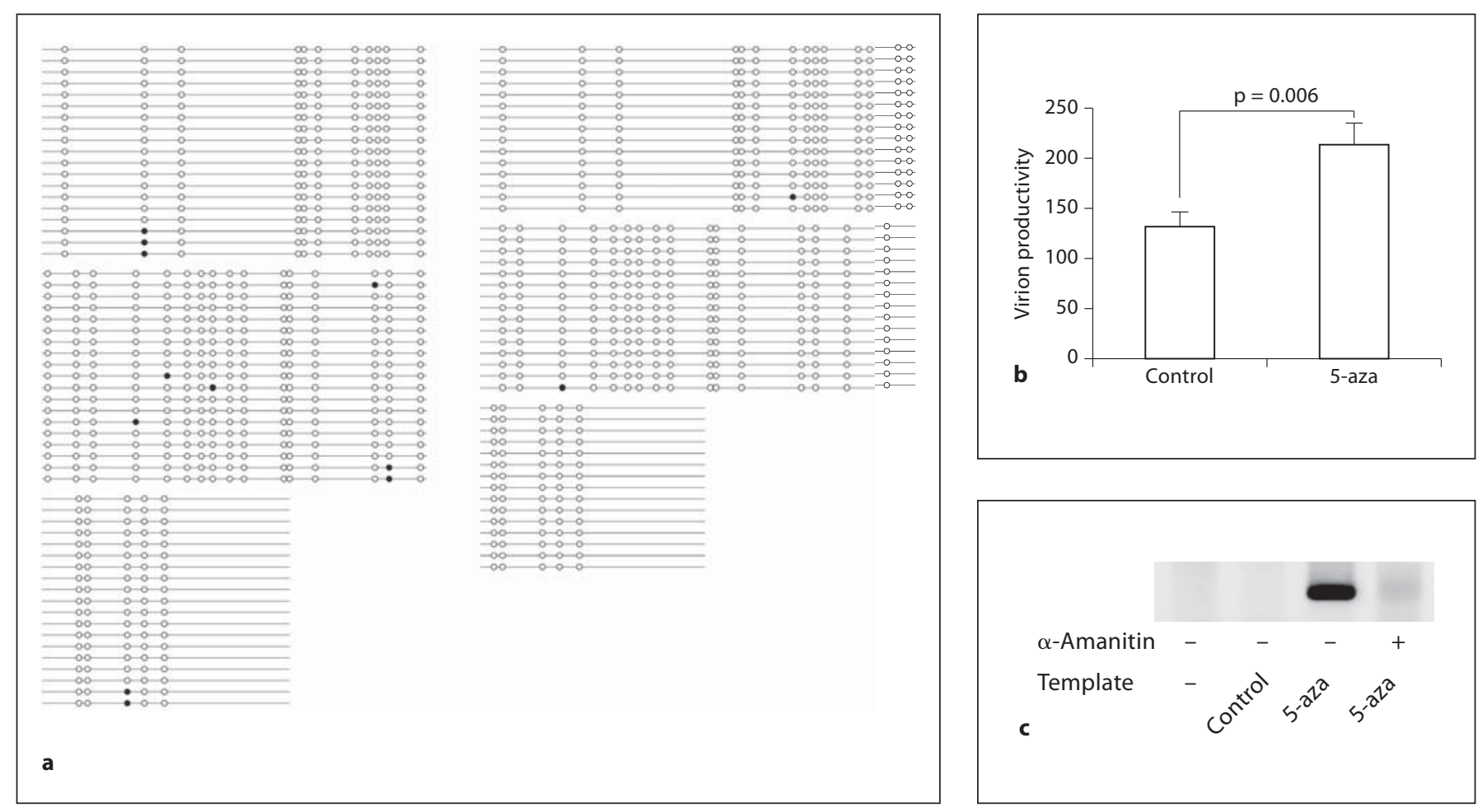

Fig. 3. Relationship between methylation and transcriptional activity of HBV cccDNA in a human hepatoma cell line. HepAD38 cells were cultured without tetracycline for 3 days to induce HBV replication and further incubated in the presence of tetracycline with or without daily 5 -aza replenishment for 9 days before isolation of cccDNA. a Bisulfite sequencing of isolated HBV cccDNA showed that $\mathrm{CpG}$ methylation increased over time in the control cells (left panel), whereas 5-aza suppressed CpG methylation (36\% of control; right panel). b Virion productivity, on the other hand, was 1.61 times higher in the 5-aza group compared to the control group $(\mathrm{p}<0.05)$. Error bars represent the SD of triplicate measure- ments. c In vitro transcription assay of $\mathrm{HBV}$ cccDNA from HepAD38 cells. The above-studied HBV cccDNAs (before bisulfite modification) were used as templates for a nuclear run-off assay. RT-PCR of the run-off transcripts showed that HBV cccDNA with increased $\mathrm{CpG}$ methylation had suppressed transcriptional activity (control); however, transcriptional activity could be detected from HBV cccDNA with suppressed methylation (5-azatreated cells). $\alpha$-Amanitin was used to confirm that the RT-PCR amplicon was from the transcripts synthesized by RNA polymerase II, rather than from contaminating HBV DNA templates. related with the cccDNA methylation ratio $(r=-0.689$, $\mathrm{p}=0.013$; fig. $2 \mathrm{~b}$ ). The mean virion productivity tended to be lower in the high-methylation ratio group compared to the low-methylation ratio group, although the significance was marginal ( 3.0 vs. 11.4 , respectively; $\mathrm{p}=$ $0.05)$.

The real-time RT-PCR assays showed significant correlation between the hepatic HBV RNA levels and the virion productivity (fig. 2c). The relative copy numbers of HBV RNA produced per cccDNA molecule, an estimate of the transcriptional activity of cccDNA, were significantly lower in the high-methylation ratio group compared to the low-methylation ratio group $(\mathrm{p}=0.049$; fig. 2d), again supporting the hypothesis that methylation of cccDNA suppresses replicative activity.

\section{CpG Methylation Is Associated with Suppressed Transcriptional Activity of HBV cccDNA}

The relationship between cccDNA methylation and the replicative activity of HBV was further examined by in vitro experiments. When HepAD38 cells were replenished with 5-aza, cccDNA methylation was suppressed (fig. 3a) and the virion productivity was increased (fig. 3b) compared to the control without 5-aza treatment. To exclude the possibility that HBV replication was directly affected by 5 -aza, we performed an in vitro transcription assay using the HBV cccDNAs with known methylation status as templates (cccDNAs that were analyzed for methylation as shown in figure 3a). Indeed, cccDNAs with increased methylation showed suppressed transcriptional activity compared to cccDNAs with minimal 
methylation (fig. 3c). In addition, an in vitro transcription assay using the cccDNAs from $2 \mathrm{HBeAg-negative} \mathrm{pa-}$ tients also showed suppression of transcriptional activity by increased methylation (fig. 4).

\section{HBV cccDNA Is Bound by MBDI}

Finally, we examined whether the cccDNA recruited transcriptional repressor proteins (MBPs [34] and DNMT3a [35]) which may suppress viral transcription. Chromatin immunoprecipitation assays showed that MBD1 was bound to cccDNA in HepAD38 cells, whereas antibodies against $\mathrm{MeCP} 2$ and DNMT3a did not precipitate $\mathrm{HBV}$ cccDNA (fig. 5).

\section{Discussion}

Recently, epigenetic modifications, especially the status of cccDNA-bound histones, were shown to influence cccDNA function $[33,36]$. Since DNA methylation and histone deacetylation constitute two related epigenetic mechanisms of transcriptional repression in eukaryotic cells, it can be hypothesized that methylation of cccDNA may also influence HBV replication [37-39]. To our knowledge, only two previous papers have reported the presence of cccDNA methylation in CHB $[11,12]$. These reports also suggested an association between cccDNA methylation and suppressed viral replication. The study by Guo et al. [12] included only patients with an HBV viral load of $>10^{3}$ copies $/ \mathrm{ml}$; since a significant proportion of HBeAg-negative patients may have undetectable serum HBV titers [40], these patients might have been systematically excluded in their study. The study by Vivekanandan et al. [11] included cccDNA samples from liver cancer tissues, and the frequencies of cccDNA methylation were not quantitatively correlated to the HBV viral loads. In both reports, the presence of combined liver cirrhosis was not specified. Considering the possible interactions between the HBV viral load and the presence of severe fibrosis (cirrhosis) [41, 42], we focused our study on HBV-LC regardless of $\mathrm{HBV}$ viral loads to elucidate the factors associated with cccDNA methylation in this population while minimizing the possible confounding interactions between the degree of liver fibrosis and HBV replication. Although small sample size is the main limitation of this study, our data may give a better insight into the methylation status of HBV cccDNA in liver cirrhosis patients.

Our bisulfite sequencing data show variable degrees of CpG methylation in the intrahepatic HBV cccDNA from HBV-LC patients. We also found that old age is associ-

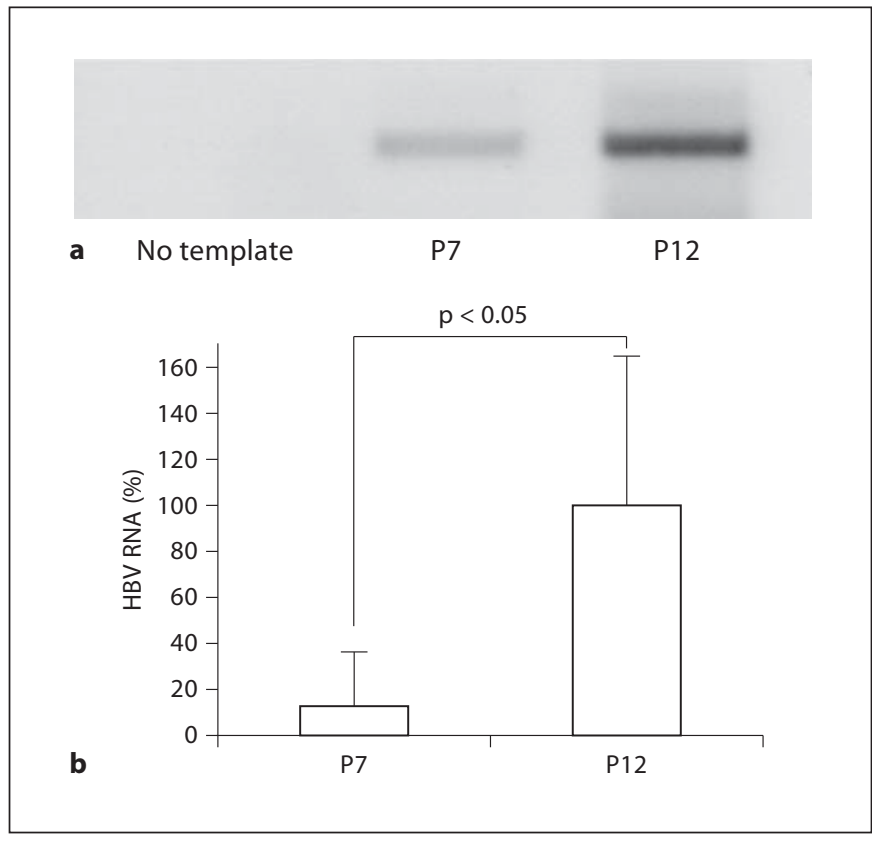

Fig. 4. In vitro transcription assay of $\mathrm{HBV}$ cccDNA from $\mathrm{HBeAg}$ negative patients. A nuclear run-off assay was performed as described in the legend to figure 3, using HBV cccDNAs from 2 HBeAg-negative patients (P7 and P12). RT-PCR of the run-off transcripts showed that $\mathrm{HBV}$ cccDNAs with increased $\mathrm{CpG}$ methylation had suppressed transcriptional activity (P7) compared to HBV cccDNAs without methylation (P12). a RT-PCR as described in figure $3 \mathbf{c}$. $\mathbf{b}$ Real-time RT-PCR for HBV rcDNA as described in Patients and Methods.

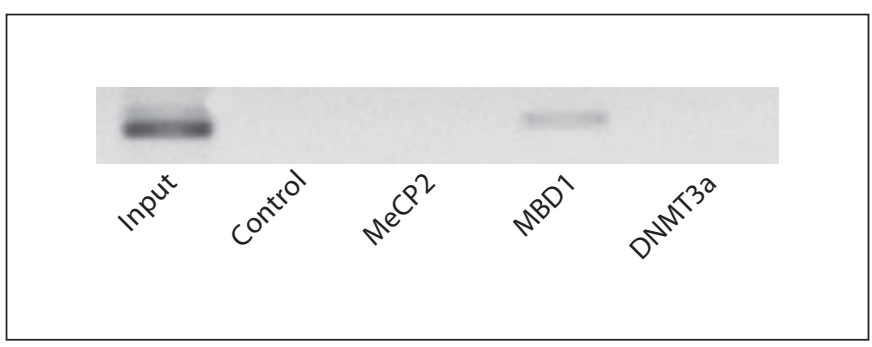

Fig. 5. Chromatin immunoprecipitation assays show that MBD1 binds HBV cccDNA. HepAD38 cells were grown in tetracyclinefree medium to induce the replication of HBV. The cells were formaldehyde-fixed on day 14 , and the nuclei were isolated, lysed and sonicated to fragment genomic DNA. Input DNA (positive control, marked as input) was extracted from the sonicated chromatin before immunoprecipitation. Normal mouse serum (marked as control), anti-MeCP2, anti-MBD1 or anti-DNMT3a antibody was used for immunoprecipitation of sonicated chromatin. DNA was extracted from immunoprecipitates and subjected to digestion with Plasmid-Safe DNase, followed by PCR amplification using primers specific for HBV cccDNA $[18,19]$. The result is a representative image of 2 independent experiments. 
ated with increased methylation. Considering the epidemiology of HBV infection in Korea, where perinatal infection is the main mode of transmission, a patient's age may correspond to the duration of HBV infection [43]. Thus, it could be argued that methylation of cccDNA accumulates over time. Since HBV cccDNA is quite stable in quiescent hepatocytes [5], methylated cccDNA may be passed to daughter cells after mitotic division, and additional methylation on replenished cccDNA may increase the methylation frequency of the cccDNA population in chronic HBV infection.

The association between cccDNA methylation and suppressed serum HBV DNA titers in HBV-LC suggests that methylation regulates the replicative activity of cccDNA in these patients. This hypothesis is further supported by our data showing that (1) cccDNA methylation is negatively associated with the virion productivity in both HBV-LC and HepAD38 cells, (2) HBV RNA copy numbers generated per cccDNA, another indicator of the activity of cccDNA [3, 4], are suppressed in HBV-LC with elevated cccDNA methylation and (3) cccDNA methylation directly suppresses transcriptional activity in in vitro transcription assays using cccDNA templates from HepAD38 cells and HBV-LC patients. Taken together, these results suggest the possibility that increased HBV cccDNA methylation may contribute to suppressed viral productivity in HBV-LC.

Our data showed that increased cccDNA methylation was associated with older age and a low serum HBV DNA titer, and these factors are generally associated with HBeAg clearance [44]. Previous studies demonstrated suppressed replicative activity of cccDNA in HBeAg-negative $\mathrm{CHB}[3,4]$. Therefore, it can be postulated that $\mathrm{HBeAg}$ clearance is associated with increased cccDNA methylation, which in turn leads to suppressed viral productivity. Indeed, a recent study reported increased cccDNA methylation in HBeAg-negative CHB [12], but our results did not show a significant relation between HBeAg positivity and cccDNA methylation. The small sample size in our study may explain this discrepancy, but it is also possible that the methylation status of cccDNA may be similar regardless of $\mathrm{HBeAg}$ positivity in liver cirrhosis. As our study population was limited to patients with pathologically proven liver cirrhosis, and other factors such as host immunity may also affect viral productivity, the overall quantitative contribution of cccDNA methylation to the transcriptional regulation of HBV in chronic HBV infection needs validation in different stages of HBV infection in further studies.

Our study also gives clues to the mechanism of in vitro transcriptional block by cccDNA methylation. Methylation of mammalian DNA induces transcriptional silencing by recruiting MBPs which function as methylationdependent transcriptional repressors [45]. MBDs are a major family of MBPs in vertebrates and include MBD1, MBD2, MBD3, MBD4 and MeCP2 [34, 45]. DNMT3a has also been reported to function as a corepressor of transcription [35]. Our ChIP data showed that MBD1 is bound to $\mathrm{HBV}$ cccDNA, suggesting that methylated CpG recruits MBD1, which might lead to transcriptional repression of methylated cccDNA. Further studies are warranted to confirm the mechanism(s) of transcriptional suppression by cccDNA methylation in human specimens.

In conclusion, HBV cccDNA is variably methylated, and methylation of cccDNA is associated with suppressed viral replicative activity in HBV-LC.

\section{Acknowledgments}

We thank So Hyun Shin, Seung Hee Shim and Ji Hye Lee for technical assistance. This work was funded in full by the Seoul National University Bundang Hospital Research Fund (02-2007034 to J.-W.K.).

\section{References}

1 Seeger C, Mason WS: Hepatitis B virus biology. Microbiol Mol Biol Rev 2000;64:51-68.

$\checkmark 2$ Werle-Lapostolle B, Bowden S, Locarnini S, Wursthorn K, Petersen J, Lau G, Trepo C, Marcellin P, Goodman Z, Delaney WE 4th, Xiong S, Brosgart CL, Chen SS, Gibbs CS, Zoulim F: Persistence of cccDNA during the natural history of chronic hepatitis B and decline during adefovir dipivoxil therapy. Gastroenterology 2004;126:1750-1758.
3 Laras A, Koskinas J, Dimou E, Kostamena A, Hadziyannis SJ: Intrahepatic levels and replicative activity of covalently closed circular hepatitis B virus DNA in chronically infected patients. Hepatology 2006;44:694-702.

4 Volz T, Lutgehetmann M, Wachtler P, Jacob A, Quaas A, Murray JM, Dandri M, Petersen $\mathrm{J}$ : Impaired intrahepatic hepatitis B virus productivity contributes to low viremia in most HBeAg-negative patients. Gastroenterology 2007;133:843-852.
5 Levrero M, Pollicino T, Petersen J, Belloni L, Raimondo G, Dandri M: Control of cccDNA function in hepatitis B virus infection. J Hepatol 2009;51:581-592.

6 Miller RH, Robinson WS: Integrated hepatitis B virus DNA sequences specifying the major viral core polypeptide are methylated in PLC/PRF/5 cells. Proc Natl Acad Sci USA 1983;80:2534-2538. 
7 Korba BE, Wilson VL, Yoakum GH: Induction of hepatitis B virus core gene in human cells by cytosine demethylation in the promoter. Science 1985;228:1103-1106.

$\checkmark 8$ Bowyer SM, Dusheiko GM, Schoub BD, Kew MC: Expression of the hepatitis B virus genome in chronic hepatitis B carriers and patients with hepatocellular carcinoma. Proc Natl Acad Sci USA 1987;84:847-850.

9 Araki K, Akagi K, Miyazaki J, Matsubara K, Yamamura K: Correlation of tissue-specific methylation with gene inactivity in hepatitis $B$ virus transgenic mice. Jpn J Cancer Res 1990;81:1265-1271.

10 Pourcel C, Tiollais P, Farza H: Transcription of the $\mathrm{S}$ gene in transgenic mice is associated with hypomethylation at specific sites and with DNase I sensitivity. J Virol 1990;64: 931-935.

-11 Vivekanandan P, Thomas D, Torbenson M: Methylation regulates hepatitis B viral protein expression. J Infect Dis 2009;199:12861291.

-12 Guo Y, Li Y, Mu S, Zhang J, Yan Z: Evidence that methylation of hepatitis B virus covalently closed circular DNA in liver tissues of patients with chronic hepatitis B modulates HBV replication. J Med Virol 2009;81:11771183.

13 Lee CZ, Huang GT, Yang PM, Sheu JC, Lai MY, Chen DS: Correlation of HBV DNA levels in serum and liver of chronic hepatitis B patients with cirrhosis. Liver 2002;22:130-135.

-14 Ladner SK, Otto MJ, Barker CS, Zaifert K, Wang GH, Guo JT, Seeger C, King RW: Inducible expression of human hepatitis B virus (HBV) in stably transfected hepatoblastoma cells: a novel system for screening potential inhibitors of HBV replication. Antimicrob Agents Chemother 1997;41:1715-1720.

15 Hirt B: Selective extraction of polyoma DNA from infected mouse cell cultures. J Mol Biol 1967;26:365-369.

16 Wieland SF, Spangenberg HC, Thimme R, Purcell RH, Chisari FV: Expansion and contraction of the hepatitis $B$ virus transcriptional template in infected chimpanzees. Proc Natl Acad Sci USA 2004;101:2129-2134.

17 Lo YM, Tein MS, Lau TK, Haines CJ, Leung TN, Poon PM, Wainscoat JS, Johnson PJ, Chang AM, Hjelm NM: Quantitative analysis of fetal DNA in maternal plasma and serum: implications for noninvasive prenatal diagnosis. Am J Hum Genet 1998;62:768775 .

$18 \mathrm{Lu}$ X, Block TM, Gerlich WH: Protease-induced infectivity of hepatitis B virus for a human hepatoblastoma cell line. J Virol 1996; 70:2277-2285.
19 Stoll-Becker S, Repp R, Glebe D, Schaefer S, Kreuder J, Kann M, Lampert F, Gerlich WH: Transcription of hepatitis B virus in peripheral blood mononuclear cells from persistently infected patients. J Virol 1997;71: 5399-5407.

20 Takehara T, Suzuki T, Ohkawa K, Hosui A, Jinushi M, Miyagi T, Tatsumi T, Kanazawa Y, Hayashi N: Viral covalently closed circular DNA in a non-transgenic mouse model for chronic hepatitis B virus replication. J Hepatol 2006;44:267-274.

21 Jun-Bin S, Zhi C, Wei-Qin N, Jun F: A quantitative method to detect HBV cccDNA by chimeric primer and real-time polymerase chain reaction. J Virol Methods 2003;112: 45-52.

22 Lee JY, Culvenor JG, Angus P, Smallwood R, Nicoll A, Locarnini S: Duck hepatitis B virus replication in primary bile duct epithelial cells. J Virol 2001;75:7651-7661.

-23 Sugauchi F, Mizokami M, Orito E, Ohno T, Kato H, Suzuki S, Kimura Y, Ueda R, Butterworth LA, Cooksley WG: A novel variant genotype $\mathrm{C}$ of hepatitis $\mathrm{B}$ virus identified in isolates from Australian Aborigines: complete genome sequence and phylogenetic relatedness. J Gen Virol 2001;82:883-892.

-24 An SF, Franklin D, Fleming KA: Generation of digoxigenin-labelled double-stranded and single-stranded probes using the polymerase chain reaction. Mol Cell Probes 1992;6:193200.

25 Kim JW, Zhang YH, Zern MA, Rossi JJ, Wu J: Short hairpin RNA causes the methylation of transforming growth factor-beta receptor II promoter and silencing of the target gene in rat hepatic stellate cells. Biochem Biophys Res Commun 2007;359:292-297.

26 Olek A, Oswald J, Walter J: A modified and improved method for bisulphite based cytosine methylation analysis. Nucleic Acids Res 1996;24:5064-5066.

27 Li LC, Dahiya R: Methprimer: designing primers for methylation PCRs. Bioinformatics 2002;18:1427-1431.

28 Vivekanandan P, Thomas D, Torbenson M: Hepatitis B viral DNA is methylated in liver tissues. J Viral Hepat 2008;15:103-107.

29 Nishizono A, Maeno M, Hiraga M, Hirai H, Esumi M, Shikata T: In vitro transcription of the hepatitis B virus gene by nuclear extracts of human hepatoma cells. Virology 1991;182: 545-552.

30 Dignam JD, Lebovitz RM, Roeder RG: Accurate transcription initiation by RNA polymerase II in a soluble extract from isolated mammalian nuclei. Nucleic Acids Res 1983; 11:1475-1489.

31 Weinmann AS, Farnham PJ: Identification of unknown target genes of human transcription factors using chromatin immunoprecipitation. Methods 2002;26:37-47.

-32 Shang Y, Myers M, Brown M: Formation of the androgen receptor transcription complex. Mol Cell 2002;9:601-610.
Pollicino T, Belloni L, Raffa G, Pediconi N, Squadrito G, Raimondo G, Levrero M: Hepatitis $B$ virus replication is regulated by the acetylation status of hepatitis B virus $\mathrm{cccD}$ NA-bound $\mathrm{H} 3$ and H4 histones. Gastroenterology 2006;130:823-837.

34 Clouaire T, Stancheva I: Methyl-CpG binding proteins: specialized transcriptional repressors or structural components of chromatin? Cell Mol Life Sci 2008;65:1509_ 1522.

35 Fuks F, Burgers WA, Godin N, Kasai M, Kouzarides T: Dnmt3a binds deacetylases and is recruited by a sequence-specific repressor to silence transcription. ЕMBO J 2001;20:2536-2544.

36 Belloni L, Pollicino T, De Nicola F, Guerrieri F, Raffa G, Fanciulli M, Raimondo G, Levrero M: Nuclear HBx binds the HBV minichromosome and modifies the epigenetic regulation of cccDNA function. Proc Natl Acad Sci USA 2009;106:19975-19979.

37 Newbold JE, Xin H, Tencza M, Sherman G, Dean J, Bowden S, Locarnini S: The covalently closed duplex form of the hepadnavirus genome exists in situ as a heterogeneous population of viral minichromosomes. J Virol 1995;69:3350-3357.

38 Bock CT, Schwinn S, Locarnini S, Fyfe J, Manns MP, Trautwein C, Zentgraf H: Structural organization of the hepatitis $B$ virus minichromosome. J Mol Biol 2001;307:183196.

39 Vaissiere T, Sawan C, Herceg Z: Epigenetic interplay between histone modifications and DNA methylation in gene silencing. Mutat Res 2008;659:40-48.

40 McMahon BJ: The natural history of chronic hepatitis B virus infection. Hepatology 2009; 49:S45-S55.

41 Wong DK, Yuen MF, Tse E, Yuan H, Sum SS, Hui CK, Lai CL: Detection of intrahepatic hepatitis B virus DNA and correlation with hepatic necroinflammation and fibrosis. J Clin Microbiol 2004;42:3920-3924.

42 Bayram A, Erkilic S, Ozkur A, Bayram M, Sari I: Quantification of intrahepatic total hepatitis B virus DNA in chronic hepatitis B patients and its relationship with liver histology. J Clin Pathol 2008;61:338-342.

43 Ahn YO: Strategy for vaccination against hepatitis B in areas with high endemicity: focus on Korea. Gut 1996;38(suppl 2):S63S66.

44 Lok AS, McMahon BJ: Chronic hepatitis B: update 2009. Hepatology 2009;50:661-662.

45 Klose RJ, Bird AP: Genomic DNA methylation: the mark and its mediators. Trends Biochem Sci 2006;31:89-97. 